Research Paper: PA-Precision Agriculture

\title{
A tractor-mounted scanning LIDAR for the non-destructive measurement of vegetative volume and surface area of tree-row plantations: A comparison with conventional destructive measurements
}

\author{
Joan Ramon Rosell Polo ${ }^{a, *}$, Ricardo Sanz ${ }^{a}$, Jordi Llorens ${ }^{d}$, Jaume Arnó ${ }^{a}$, Alexandre Escolà ${ }^{a}$, \\ Manel Ribes-Dasi ${ }^{a}$, Joan Masip ${ }^{a}$, Ferran Camp ${ }^{c}$, Felip Gràcia ${ }^{c}$, Francesc Solanelles ${ }^{c}$, \\ Tomàs Pallejà $^{b}$, Luis Val ${ }^{e}$, Santiago Planas ${ }^{a}$, Emilio Gil ${ }^{d}$, Jordi Palacín ${ }^{b}$ \\ ${ }^{a}$ Department of Agro-forestry Engineering, University of Lleida, Avinguda Rovira Roure, 191, 25198 Lleida, Spain \\ ${ }^{b}$ Department of Informatics and Industrial Engineering, University of Lleida, Spain \\ ${ }^{c}$ Centre de Mecanització Agrària, Agriculture, Food and Rural Action Department, Generalitat de Catalunya, Lleida, Spain \\ ${ }^{\mathrm{d} D e p a r t m e n t}$ of AgriFood Engineering and Biotechnology, Politechnical University of Catalunya, Spain \\ e Department of Mechanization and Agricultural Technology, Politechnical University of Valencia, Spain
}

\section{A R T I C L E I N F O}

\section{Article history:}

Received 9 March 2008

Received in revised form

7 October 2008

Accepted 23 October 2008

Available online 4 December 2008

\begin{abstract}
The use of a low-cost tractor-mounted scanning Light Detection and Ranging (LIDAR) system for capable of making non-destructive recordings of tree-row structure in orchards and vineyards is described. Field tests consisted of several LIDAR measurements on both sides of the crop row, before and after defoliation of selected trees. Summary parameters describing the tree-row volume and the total crop surface area viewed by the LIDAR (expressed as a ratio with ground surface area) were derived using a suitable numerical algorithm. The results for apple and pear orchards and a wine producing vineyard were shown to be in reasonable agreement with the results derived from a destructive leaf sampling method. Also, good correlation was found between manual and sensor-based measurements of the vegetative volume of tree-row plantations. The Tree Area Index parameter, TAI, gave the best correlation between destructive and non-destructive (i.e. LIDAR-based) determinants of crop leaf area. The LIDAR system proved to be a powerful technique for low cost, prompt and non-destructive estimates of the volume and leaf-area characteristics of plants.
\end{abstract}

(c) 2008 IAgrE. Published by Elsevier Ltd. All rights reserved.

\section{Introduction}

The measurement and structural characterisation of plants can be carried out by means of several detection principles, including image analysis techniques, stereoscopy photography, analysis of the light spectrum, infrared thermography, ultrasonic ranging and optical ranging; the last being the method applied to this study.

Light Detection and Ranging (LIDAR) is a remote sensing technique based on the measurement of the time a laser pulse

\footnotetext{
* Corresponding author.

E-mail address: jr.rosell@eagrof.udl.cat (J.R. Rosell Polo).

1537-5110/\$ - see front matter ( 2008 IAgrE. Published by Elsevier Ltd. All rights reserved. doi:10.1016/j.biosystemseng.2008.10.009
} 


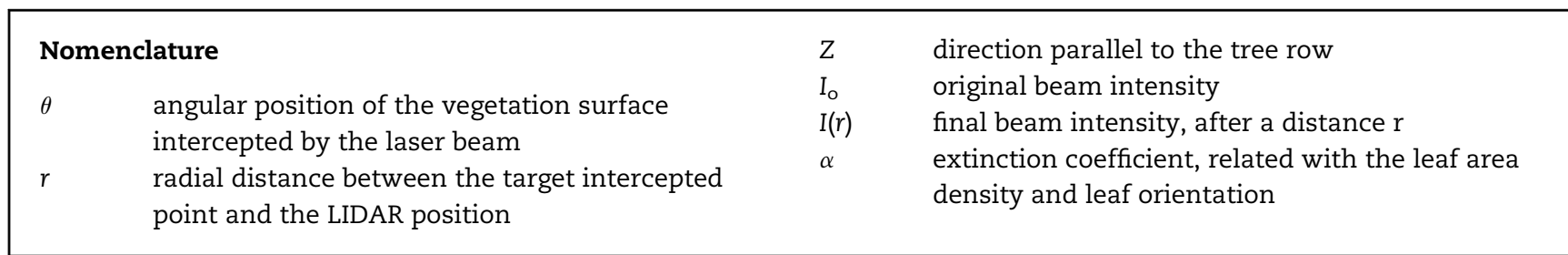

takes between the sensor and a target. LIDAR for vegetation studies usually involves the use of near-infrared radiation, although, sometimes, visible light is also used. This radiation reflects off leaves, branches and other elements and is returned to the instrument. The elapsed time between the transmission of the pulsed laser beam and the reception of its echo, sometimes called time-of-flight, is used to measure the distance between the scanner and the surface of the reflecting object. In recent years, LIDAR sensors have been widely used for the measurement of environmental parameters, particularly for the characterisation of forest and agricultural systems (Ritchie et al., 1993; Nilsson, 1996; Lefsky et al., 1999; Wehr and Lohr, 1999; Harding et al., 2001; Holmgrena and Persson, 2004; Kotchenova et al., 2004; Parker et al., 2004). Although the majority of these measurements were carried out using LIDAR sensors mounted on aircraft or satellites, measurements can be based on terrestrial or ground-based LIDAR sensors (e.g. Walklate et al., 2002; Tumbo et al., 2002; Wei and Salyani, 2004; Van der Zande et al., 2006; Palacín et al., 2007). The advantages of ground-based LIDAR are that can be simple to operate and inexpensive. When used in conjunction with multispectral sensors, LIDAR sensors can provide detailed three-dimensional (3D) information on land-cover. Moreover, they can induce fluorescence in plants allowing them to be used to monitor plant health on a large scale.

For agriculture applications, Walklate et al. (2002) proposed a methodology for managing and computing laser sensor data to obtain several parameters related to the geometric characteristics of apple trees (height, volume) and to some properties that define the structural characteristics of trees (foliage density and foliage distribution). Subsequently, they evaluated the comparative performance of different pesticide deposition models by means of LIDAR field measurements of crop structure and leaf deposit measurements on Cox apple trees using different combinations of rootstock, plantation density, age and growth stage.

Usually, the structural and geometrical parameters of trees, such as vegetative volumes and areas, are derived from the manual measurement of heights and widths and the destructive sampling of leaves. However, because destructive sampling for fruit orchards is both slow and costly, other inexpensive methods, such as ground-based LIDAR scanning systems, have been used over the last 10 years and found to be robust. Since 1995, much effort has been addressed at the University of Lleida on the determination of the geometry and other structural parameters of plants - such as Leaf Area Index (LAI) - using non-destructive methods based on the use of ultrasonic sensors and, more recently, ground-based LIDAR scanners (Sanz et al., 2004). In this work, in order to determine the suitability of laser sensors to characterise fruit trees and vineyards, several parameters have been computed based on scanner data, and compared with foliage areas and plant volume by means of linear regression analysis. The procedures developed and the results obtained are presented here.

\section{Materials and methods}

\subsection{LIDAR scanner}

The LIDAR scanner used in this experimental work was a lowcost general-purpose LMS-200 model (Sick, Düsseldorf, Germany) (Fig. 1), with accuracy of $\pm 15 \mathrm{~mm}$ and $5 \mathrm{~mm}$ standard deviation in a range up to $8 \mathrm{~m}$, a selectable angular resolution of $1^{\circ}, 0.5^{\circ}$ or $0.25^{\circ}$ and a scanning angle of $180^{\circ}$ (although the scanning angle reduced to $100^{\circ}$ when the $0.25^{\circ}$ resolution was selected). In this study, an angular resolution of $1^{\circ}$ and a scanning angle of $180^{\circ}$ were used.

The LMS-200 has a standard RS232 serial port for data transfer with a selectable rate of $9.6,19.2$ or $38.4 \mathrm{Kbit} \mathrm{s}^{-1}$. MATLAB 6.5 software (The Mathworks Inc., Natick, MA, USA) installed on a laptop was used for data acquisition and process support.

When the laser beam is intercepted by the surface of vegetation, the sensor determines from the reflected signal the angular position $\theta$ and the radial distance $r$ between the target interception point and LIDAR position (Fig. 1). The sensor continuously measures distances at the selected angular resolution. In this work, this occured every degree in a $0-180^{\circ}$ window. This information represented a vertical outline (or slice) of the tree for the current position of the LIDAR. When moved along the rows, the LIDAR scanner supplied a cluster or cloud of plant interception points in polar coordinates $(r, \theta)$, according to reference system shown in Fig. 1.

Although the LMS-200 LIDAR is a 2D laser scanner, the displacement of the laser sensor along the direction $(Z)$ parallel to the row of trees at a known constant speed, and the use of software allowed a 3D graphic representation of the cloud of plants interception points to be developed, such that a non-destructive record of the tree-row structure of the crop was obtained. Once the 3D cloud of points was obtained, efforts were focused on obtaining the geometrical and structural parameters of the tree and bush crops under examination.

\subsection{Field tests}

The LIIDAR-based system was used to characterise some common Spanish tree and bush crops. The species analysed were pear (Pyrus communis L. cv. 'Conference' and 'Blanquilla'), apple (Malus communis L. cv. 'Golden' and 'Redchief') and grapes (Vitis vinifera L. cv. 'Cabernet Sauvignon' and 'Merlot'). 

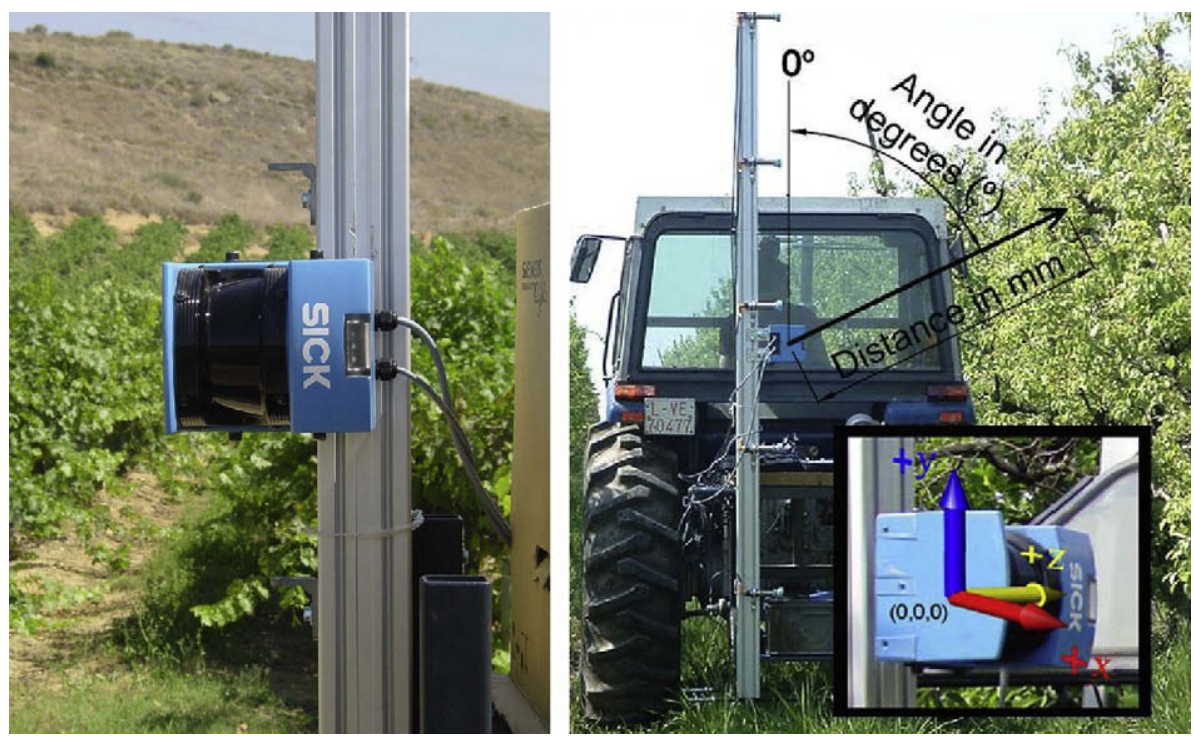

Fig. 1 - LIDAR system for field test in vineyard (left) and pear orchards (right), also showing polar (distance, $r$, and angle, $\theta$ ) and Cartesian $(x, y, z)$ coordinates reference systems.

\subsection{LIDAR measurements}

Measurements were made using a tractor-mounted LIDAR system that traversed the crop in direction $Z$, parallel to the row at a known and constant speed (between $1 \mathrm{~km} \mathrm{~h}^{-1}$ and $2 \mathrm{~km} \mathrm{~h}^{-1}$, depending on the crop), in a straight line, and at between $1 \mathrm{~m}$ and $2 \mathrm{~m}$ from the row axis, depending on the crop (Figs. 1 and 2). The laser sensor was located, at approximately half the maximum height of the trees $(2.1 \mathrm{~m}$, in the case of fruit trees and $1.6 \mathrm{~m}$, in the case of vineyards). The exact location of each vertical slice along the tree-row line ( $Z$ axis) was determined from the known forward travel speed of the LIDAR sensor which was kept constant during each trial. From each test, the accumulation of vertical slices corresponding to different positions along the tree-row line provided a cloud of intersection points which was, in effect, a 3D image of the structure of the row. Each field test consisted of several runs (or measurements) with the LIDAR sensor, on both sides of the row, as shown in Fig. 2, before and after the defoliation of the selected trees. This methodology was repeated four times coinciding with different growth stages of crops. In the field tests carried out with fruit trees and vineyards, a zone of $4 \mathrm{~m}$ and $2 \mathrm{~m}$ length, respectively, was scanned and later defoliated into four sections of $1 \mathrm{~m}$ and $0.5 \mathrm{~m}$, respectively (Fig. 3). This procedure allowed the sensor data to be compared with the 16 experimental values of crop leaf surface values obtained by manual measurements. As a result, 3D images of the crops could be rebuilt from the cloud of points obtained based on the laser scanner measurements, an example of which is shown in Fig. 4. Once the 3D images were built, several geometrical and structural parameters of the vegetation, such as volume and leaf area of trees, could be determined.

\subsection{Manual measurements of volume and leaf area of trees}

To compare with the LIDAR results, the volumes and leaf areas of trees were measured manually. Firstly, several representative trees were chosen. The measurement of the volume of a tree began with the measurement, of the maximum tree height and the height of the bare trunk in a plane perpendicular to the row containing the trunk axis. Secondly, by subtracting both previous heights, the height of the foliated part of the tree was calculated. Next, the foliated part was divided into zones of $500 \mathrm{~mm}$ high and variable
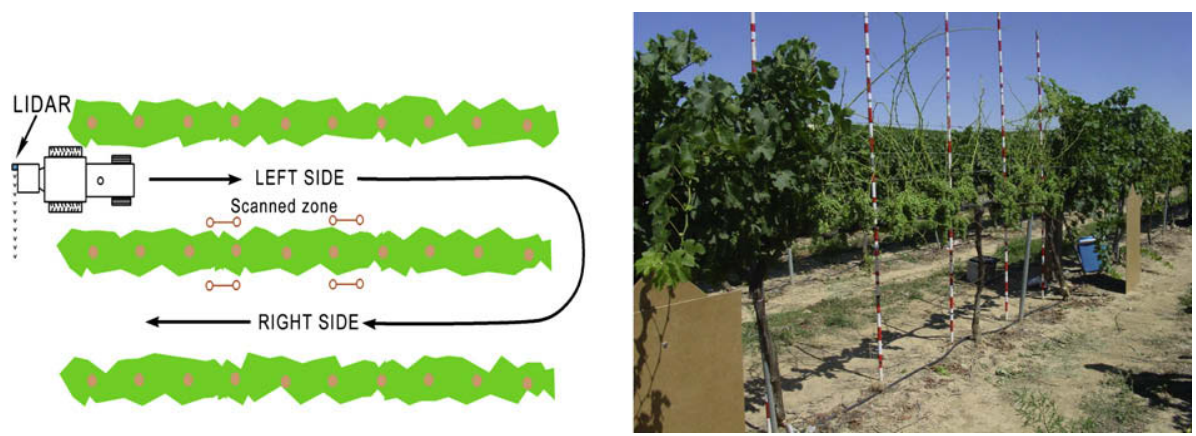

Fig. 2 - Scheme of field tests (left) and a vineyard defoliated zone (right). 


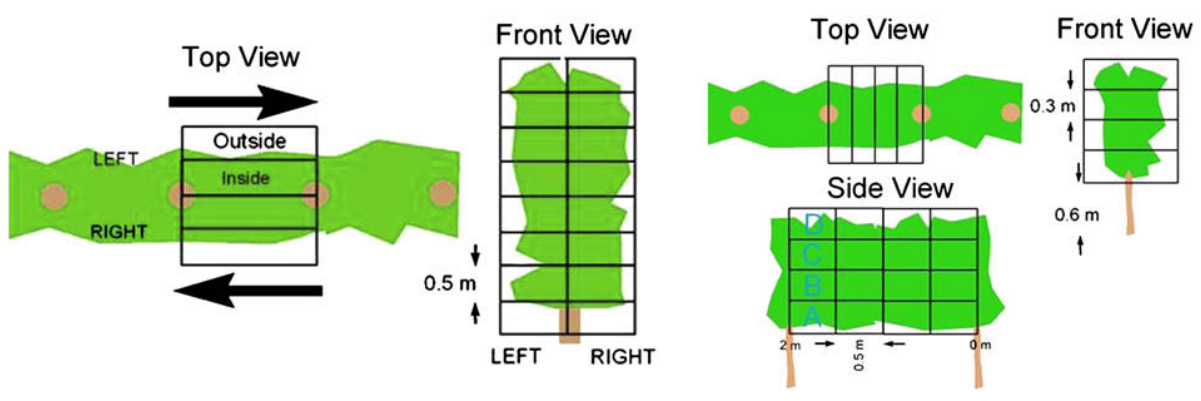

Fig. 3 - Left: top and front views of the distribution of the defoliation boxes for fruit trees. Right: top, front and side views of the distribution of the defoliation boxes for fruit vineyard.

widths (Fig. 5). The width of the vegetation corresponding to each $500 \mathrm{~mm}$ height was measured both in the perpendicular plane of the trunk and in the perpendicular plane halfway between two consecutive trunks. The zones situated at the same height of both perpendicular planes have, in general, different trapezoidal sections. The area of each trapezium was calculated by multiplying the mean value of the top and bottom widths by the corresponding height. After calculating the area of each trapezium, the mean cross-sectional area of a zone was calculated. The product of the mean crosssectional area and the distance between two consecutive trunks allowed the approximate volume of each zone to be known. Finally, the volume of the tree was obtained by summing the volumes of each zone.

For leaf area measurements, trees were divided in several volumes, as shown in Fig. 3, and separately defoliated, in order to obtain as much information as possible about the distribution of leaves in the trees, and to look for correlations with the LIDAR results. Once in the laboratory, the one-sided projected area of the leaves was measured via a shadowgraph measurement technique using an Area Measurement System-Conveyor Belt Unit (Delta-T Devices Ltd, Cambridge, UK). As a result, the onesided projected area of each volume was obtained.

\section{Results and discussion}

\subsection{LIDAR non-destructive tree-volume measurement}

So far as tree volume is concerned, manually determined and LIDAR obtained results were not identical but a simple relationship existed between the values as is shown for example, in Fig. 6 for a P. communis L. cv. 'Blanquilla' pear orchard. The differences come from the uncertainty that is inherent with the concept of the tree volume and the method used for its calculation.

\subsection{LIDAR non-destructive leaf area measurement}

Two methods for determining leaf area were developed.

The first was based on the relationship between the LIDAR measured plant volume and its respective total foliar area measured manually; from which LAI can be obtained. As is shown in Fig. 7, for the case of pear orchards, there exists a simple relationship between both values.

In Fig. 8 the relationship between the foliar area of each tree sector and the respective calculated LIDAR volume is

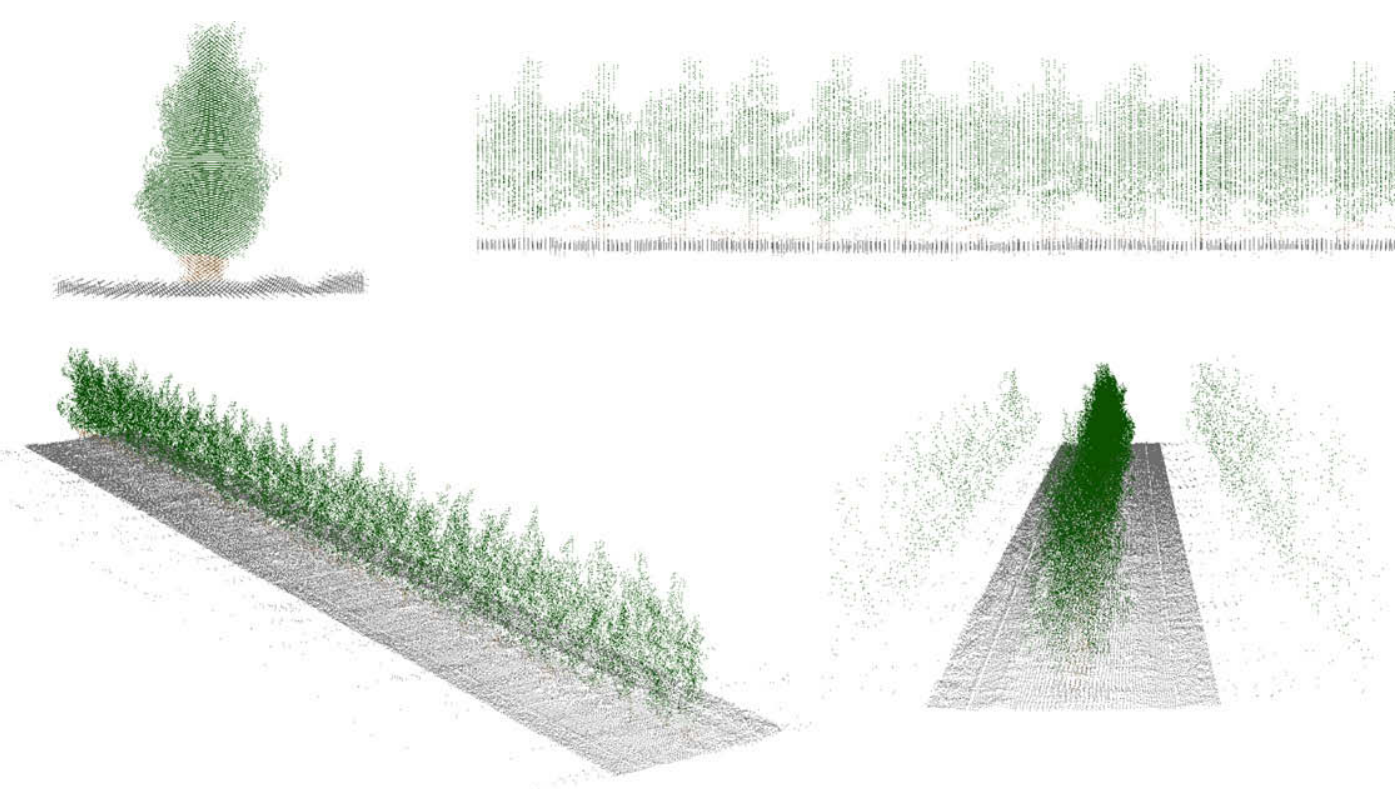

Fig 4 - Different views, depending on the position of the observer, corresponding to an apple orchard, obtained from the 3D digital model extracted from the LIDAR measurements. 


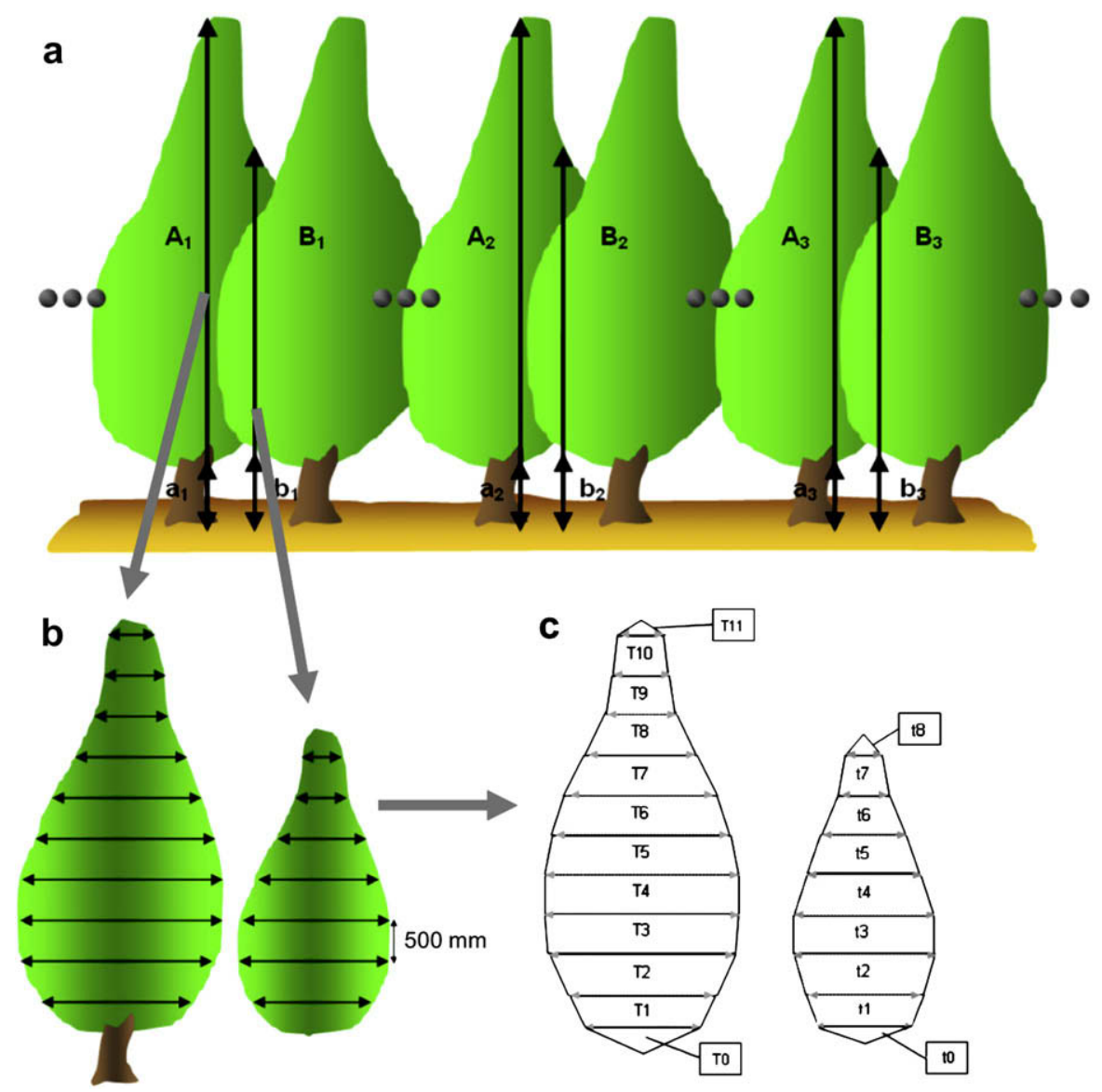

Fig. 5 - Segmentation of a tree in zones for the manual measurement of its volume. (a) A drawing of a tree-row showing three selected trees with their trunk and intermediate cross-sections, $A$ and $B$, respectively. The maximum tree heights $\left(A_{i}\right.$, $\left.B_{i}\right)$ and the height of their bare trunks $\left(a_{i}, b_{i}\right)$ are also shown. (b) Cross-section of a tree in a plane perpendicular to the treerow direction, in the trunk (left) and halfway between two consecutive trunks (right). The different widths corresponding to each $500 \mathrm{~mm}$ height divisions are also shown. (c) Cross-section of each division zone in a plane perpendicular to the treerow direction, in the trunk, Ti (left), and halfway between two consecutive trunks, ti (right).

shown. This corresponds to the sectors of seven defoliated apple trees of different ages and vegetative stages. In spite of the heterogeneity of the trees, there is a good correlation between the LIDAR volume and the foliar area (coefficient of determination $R^{2}=0.814$ ).

The second procedure is based on Beer's law and its application, from a method developed by Walklate et al. (Walklate et al., 2002; Sanz et al., 2005). According to Beer's law, the

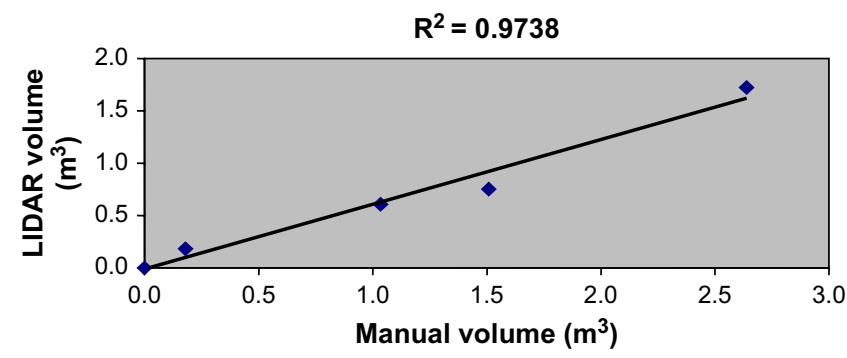

Fig. 6 - Manually $(x)$ versus LIDAR ( $y$ ) measured volume of Pyrus communis L. cv. 'Blanquilla' pear trees. The regression formula obtained was $y=0.6187 x-0.0103$. transmission of a beam of light through a plant is attenuated exponentially: $I(r)=I_{0} e^{-\alpha r}$, where $I_{0}$ and $I(r)$ are the original and the final values of beam intensity, respectively, and $\alpha$ is an extinction coefficient related to the leaf area density and leaf orientation. Among the several computed parameters proposed by Walklate et al. (2002), the Tree Area Index (TAI), formulated as the ratio between crop detected area and ground area, was chosen because of its superiority in predicting the LAI.

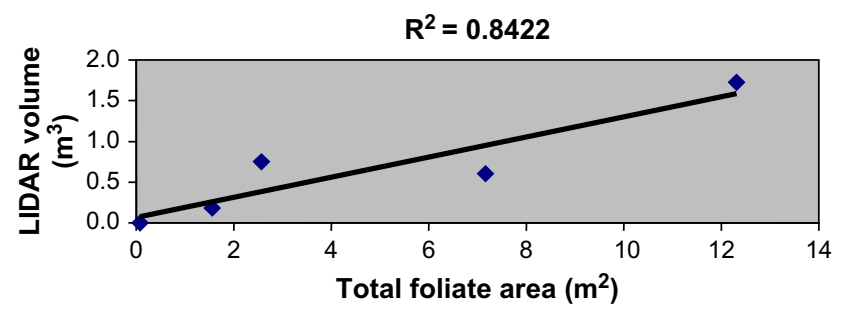

Fig. 7 - Total foliage tree area $(x)$ versus LIDAR measured volume $(y)$ of Pyrus communis L. cv. 'Blanquilla' pear trees. The regression formula obtained was $y=0.1234 x+0.0689$. 


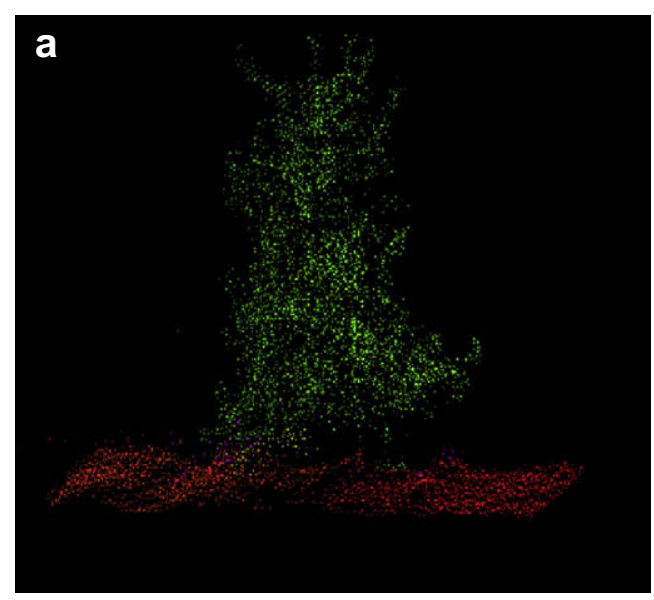

C

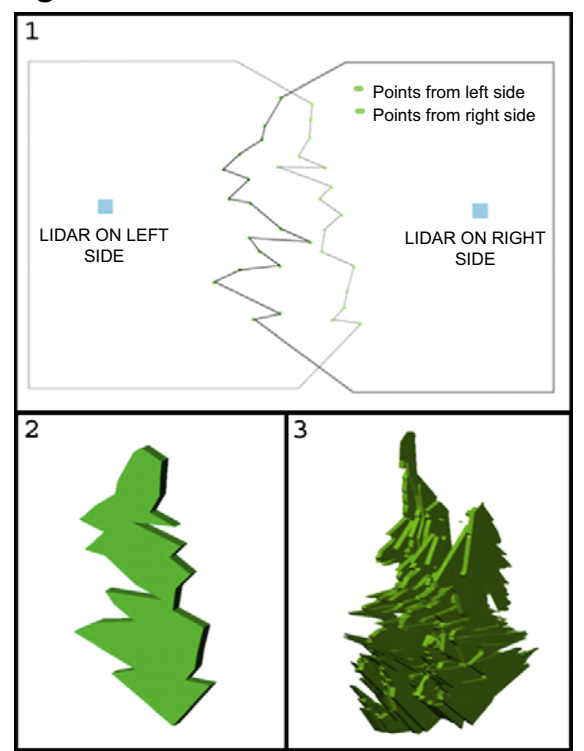

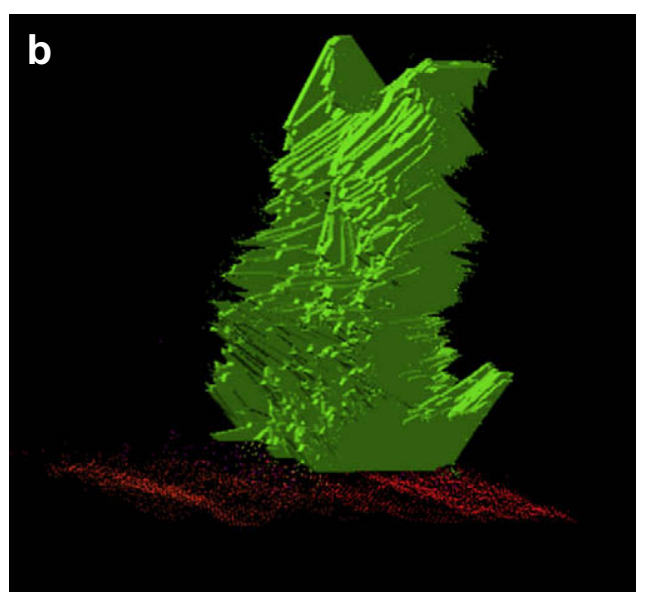

d

LIDAR measured volume vs Leaf Area Apple Trees- Malus communis L. cv.'Golden'

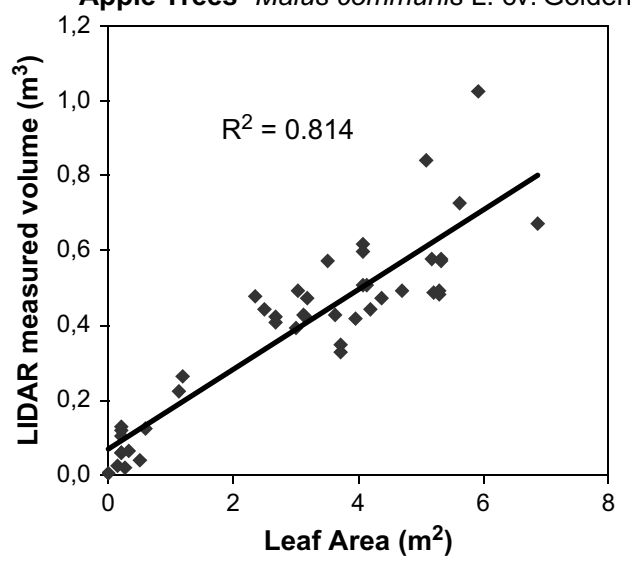

Fig. 8 - Results corresponding to a plantation of apple trees (Malus communis L. cv. 'Golden'). (a) Cloud of points generated by the LIDAR sensor. (b) Generation of global volume from the cloud of points. (c) Calculation of the volume of a single slice. (d) Correlation between LIDAR measured volume $(y)$ and leaf area $(x)$; the regression formula obtained was $y=0.1064 x+0.0712$.

This parameter was calculated for a variable number of accumulated scans (slices), corresponding to defoliated crop sections of $4 \mathrm{~m}, 2 \mathrm{~m}$ or $1 \mathrm{~m}$ length. For more reliability, the results presented in Fig. 9 are based on TAI (calculated from LIDAR non-destructive measurements) and experimental LAI (measured by manual destructive sampling) obtained from $1 \mathrm{~m}$ crop sections (64 samples). It should be pointed out that the area measurements derived from these two sampling methods are physically different. In fact, manual destructive sampling gives scalar measurements of leaf area (expressed as a one-sided projected area) while LIDAR non-destructive sampling of the optical range interception probability distribution gives a vector measurement of the total vegetative area seen by the scanning LIDAR beam, and that this includes leaves, branches and other supporting structures found in the orchard or vineyard.

The models fitted to pear orchard data showed that an acceptable degree of variability (almost 75\%) was explained by the geometric and structural parameters. For example, the canopy volume calculated slice by slice (discriminated volume) proved to be a good predictor of LAI in both the pear and apple orchards $\left(R^{2}=0.8422\right.$ and 0.814 , respectively). In vineyards the same parameter also had a high correlation $\left(R^{2}=0.8058\right)$ despite being lower than structural parameters such as TAI $\left(R^{2}=0.9194\right)$. The good correlation between the volume and area in the tree-row would appear to imply that area density is approximately constant. This may because growers tend to prune the orchards and vineyards to obtain good light penetration into the crop.

Since there was significant variability in the distribution of foliage along tree rows, and because using discriminated volumes improved the predictions for both pear orchards and vineyards, it is probably best if geometric parameters are calculated on the basis of individual slices. Nevertheless, a minimum number of slices is required to apply the principles of laser beam attenuation and Beer's law. 


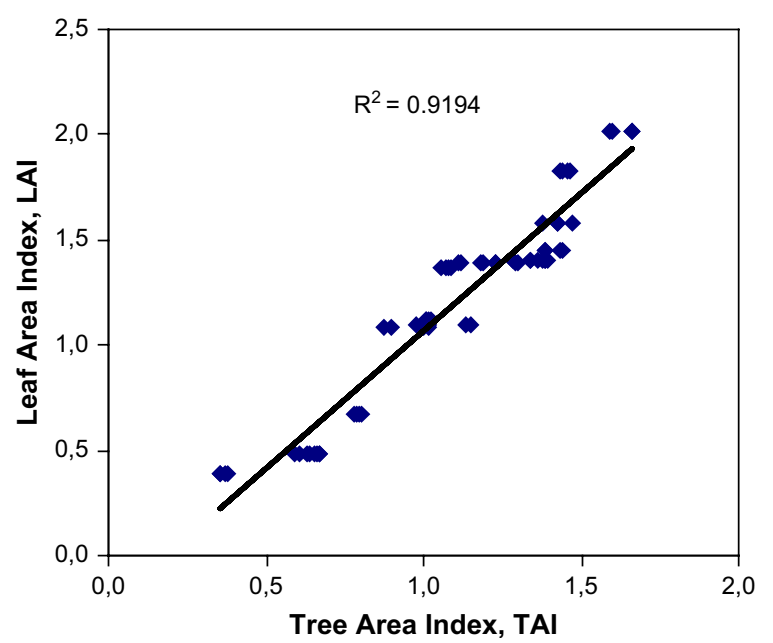

Fig. 9 - LAI prediction by means of linear regression analysis of geometric and structural parameters in vineyards. The regression formula obtained was $\mathrm{LAI}=1.3011 \mathrm{TAI}-0.2325$.

\section{Conclusions}

The LIDAR-based measurement described here system proved to be a valuable tool for the measurement of the physical and structural characteristics of plants, such as tree volume, leaf area density and LAI. LIDAR sensors can detect canopy structure differences and predict foliage density if adequate crop parameters are obtained from sensor data. Although there are differences between orchards concerning reliability of prediction models, the measurement of canopy volume (discriminated volume) predicts LAI satisfactorily for the crops tested (apple trees, pear trees and vineyards). However, TAI, was shown to be a better predictor for some specific crops.

The system could be used in precision agriculture for implementing two site-specific management techniques for the variable-rate application of crop production inputs: mapbased and sensor-based. The ability of LIDAR sensors for measuring, in a rapid and non-destructive manner, crop leaf area, tree-row volume and other crop parameters, makes this system a new and promising tool to be used as support for the decision making related to the optimisation of pesticide treatments for crop protection and other similar crop management practises. Also, this system could be an interesting tool for researchers interested in the characterisation of vegetation and its evolution with time.

\section{Acknowledgements}

This research was funded by the CICYT (Comision Interministerial de Ciencia y Tecnología, Spain), under Agreement No. AGL2002-04260-C04-02.

\section{REFERENCES}

Harding D; Lefsky M; Parker G; Blair J (2001). Laser altimeter canopy height profiles methods and validation for closedcanopy broad leaf forest. Remote Sensing of the Environment, 76, 283-297.

Holmgrena J; Persson A (2004). Identifying species of individual trees using airborne laser scanner. Remote Sensing of the Environment, 90(4), 415-423.

Kotchenova S; Song X; Shabanov N; Potter C; Knyazikhin Y; Myneni R (2004). Lidar remote sensing for modeling gross primary production of deciduous forests. Remote Sensing of the Environment, 92(2), 158-172.

Lefsky M; Cohen W; Acker S; Parker G; Spies T; Harding D (1999). Lidar remote sensing of the canopy structure and biophysical properties of douglas-fir Western Hemlock forests. Remote Sensing of the Environment, 70, 339-361.

Nilsson M (1996). Estimation of tree height and stand volume using an airborne lidar system. Remote Sensing of the Environment, 56(1), 1-7.

Palacín J; Salse J A; Sanz R; Ribes-Dasi M; Masip J; Arnó J; Llorens J; Vallès J M; Escolà A; Massana P; Camp F; Solanelles F; Rosell J R (2007). Real-time tree foliage estimation using a ground laser scanner. IEEE Transactions on Instrumentation and Measurement, 56, 1377-1383.

Parker G; Harding D; Berger M (2004). A portable LIDAR system for rapid determination of forest canopy structure. Journal of Applied Ecology, 41, 755-767.

Ritchie J; Evans D; Jacobs D; Everitt H; Weltz W (1993). Measuring canopy structure with an airborne laser altimeter. Transactions of the ASAE, 36(4), 1235-1238.

Sanz R; Palacín J; Sisó J M; Ribes-Dasi M; Masip J; Arnó J; Llorens J; Vallès J M; Rosell J R (2004). Advances in the measurement of structural characteristics of plants with a LIDAR scanner. Leuven (Belgium). In: Book of Abstracts of the AgEng 2004 Conference, pp. 400-401, Paper NR 277.

Sanz R; Llorens J; Arnó J; Vallès J M; Escolà A; Massana P; Camp F; Gil E; Palacín J; Masip J; Ribes-Dasi M; Solanelles F; Rosell J R (2005). Idoneidad y manejo de los datos de un escáner láser (LIDAR) para la caracterización de determinados parámetros vegetativos de interés en frutales y viña. [Suitability and data management of a laser scanner (LIDAR) for the characterisation of certain vegetative parameters of interest in fruit orchards and vineyards]. III Congreso Nacional de Agroingeniería, León. pp. 545-546.

Tumbo S D; Salyani M; Whitney J D; Wheaton T A; Miller W M (2002). Investigation of laser and ultrasonic ranging sensors for measurements of citrus canopy volume. Applied Engineering in Agriculture, 18(3), 367-372.

Van der Zande D; Hoet W; Jonckheere I; van Aardt J; Coppin P (2006). Influence of measurement set-up of ground-based LIDAR for derivation of tree structure. Agricultural and Forest Meteorology, 141(2-4), 147-160.

Walklate P J; Cross J V; Richardson G M; Murray R A; Baker D E (2002). Comparison of different spray volume deposition models using LIDAR measurements of apple orchards. Biosystems Engineering, 82(3), 253-267.

Wehr A; Lohr U (1999). Airborne laser scanning - an introduction and overview. ISPRS Journal of Photogrammetry and Remote Sensing, 54(2/3), 68-82.

Wei J; Salyani M (2004). Development of a laser scanner for measuring tree canopy characteristics: Phase I. Prototype development. Transactions of the ASAE, 47(6), 2101-2107. 